Classification

Physics Abstracts

61.16D -68.48

\title{
Fibre reinforcements for composite materials and electron microscopy
}

\author{
Anthony R. Bunsell \\ Ecole Nationale Supérieure des Mines de Paris, Centre des Matériaux P. M. Fourt, B. P. 8791003 Evry \\ Cedex, France \\ (Received December 20, 1990; accepted February 1, 1991)

\begin{abstract}
Résumé. - Les propriétés des composites dépendent en grande partie des renforts fibreux qui ont habituellement des diamètres de l'ordre de $10 \mu \mathrm{m}$. Ces fibres peuvent être caractérisées mécaniquement mais un compréhension des processus controlant leur comportement n'est possible que par la microscopie électronique à transmission. Les relations entre les propriétés et la microstructure de toutes classes de fibres synthétiques sont abordées dans cet article.
\end{abstract}

\begin{abstract}
Composites depend for most of their properties on the reinforcing fibres which usually have diameters of the order of $10 \mu \mathrm{m}$. These fibres can be mechanically evaluated but an understanding of the processes controlling their behaviour must use transmission electron microscopy to study mechanism at the atomic level. All classes of synthetic fibre are discussed in this paper.
\end{abstract}

\section{Introduction.}

Fibre reinforced composite materials have emerged in the last two decades from the obscurity of being considered as curiosities and now occupy the centre stage in materials development. This is because they allow the production of materials which are specifically designed for particular end uses. All classes of solids can be improved and reinforced by the addition of fibres whether it is rubber for the tyre industry which is being considered, thermosetting or thermoplastic matrices, metals, glasses or ceramics.

This important and innovative class of structural materials depends for its properties on the association of high performance fibres, which offer strength, longitudinal stiffness and low density, with a matrix material which ensures structural integrity. The high performance of such materials depends largely on the behaviour of the fibres and also on the quality of the interface between the fibres and matrix. This latter characteristic is vital as good adhesion is necessary to ensure the good load transfer through the matrix and between fibres in fibre reinforced plastics however poor adhesion is necessary in toughened fibre reinforced ceramics. 
The behaviour of fibres and of the interfaces is controlled by microscopic mechanisms which if they are to be understood require examination at the level of the atomic and molecular structure. Scanning electron microscopy can offer much in elucidating macroscopic behaviour of composites, revealing such mechanisms as fibre pull-out and matrix cracking, however a fundamental understanding of those mechanisms limiting their use requires an approach using transmission electron microscopy.

This paper will draw on studies which we have conducted on fibres with references to the works of others who have examined other aspects of this subject. For a more complete study of the whole range of fibre reinforcements and their properties it is recommended that readers turn to reference [1].

1.1 ORgANIC FIBRES. - Synthetic organic fibres first appeared in 1938 and fibres such as nylon and later polyester and aramid fibres have found extensive use in the reinforcement of rubber. Many of these rubber matrix composites such as are used as tyres or belting are subjected to repeated loading which can generate a distinctive fatigue process in the fibres.

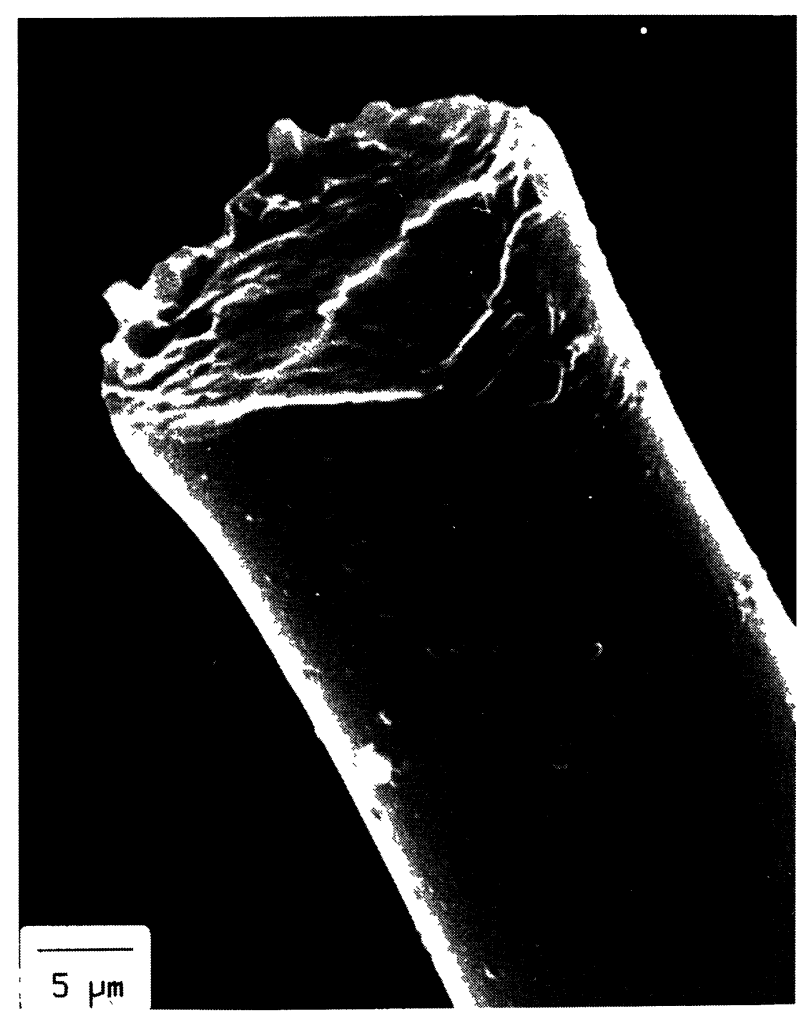

Fig. 1. - Typical tensile fracture morphology of a PET fibre (SEM image).

This type of fatigue failure occurs with maximum applied loads considerably lower than those which cause simple tensile or creep failure in a comparable interval of time and produce fracture morphologies which are very different from those found with other loading conditions. Under 
tensile or creep loading most synthetic fibres fail in a similar manner. Crack growth is initiated at the fibre surface and develops in a radial direction. The crack growth is initially stable and because of plastic deformation ahead of the crack it forms a diamond shaped wedge opening in the cylindrical fibre. Rapid failure eventually occurs when the crack has developed sufficiently for the remaining cross section no longer to be able to support the applied stress as shown in figure 1 . The two broken ends have very similar appearances with an inclined surface corresponding to slow crack growth followed by a fracture zone normal to the axis corresponding to rapid failure. Tensile fatigue crack growth is similarly initiated at or near the fibre surface but runs along the fibre at a slight angle to the axis direction. The load bearing cross section is therefore gradually reduced until if finally fails by the simple tensile or creep failure process [3], as shown in figure 2 .

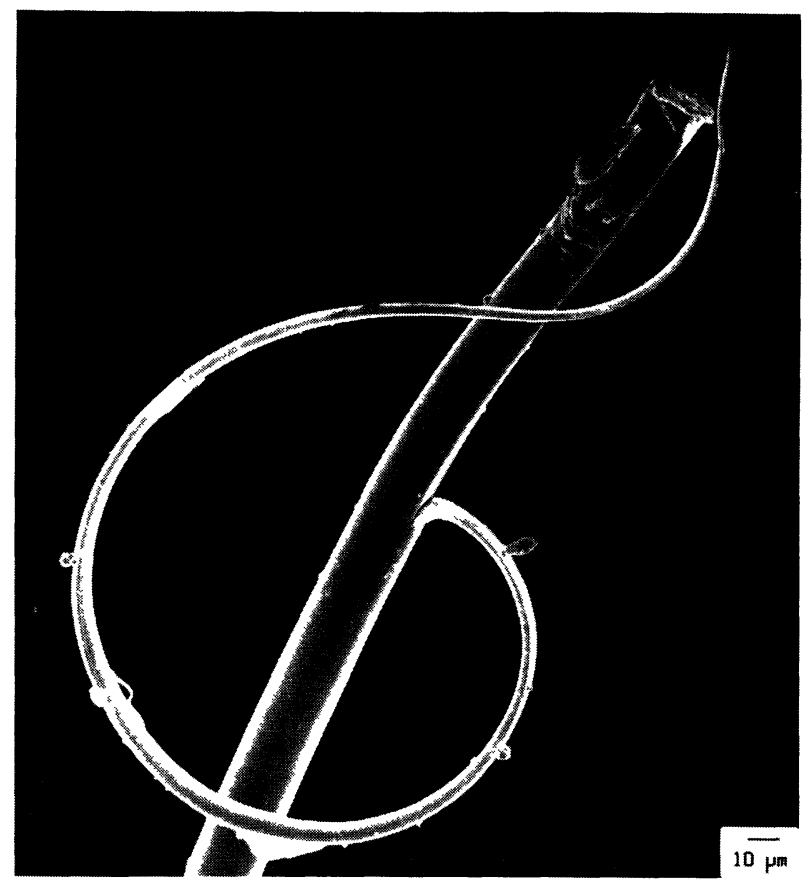

Fig. 2. - Fracture morphology of a polyester fibre broken in fatigue (SEM image).

The necessary loading criteria for fatigue failure are that the maximum cyclic load be sufficiently high, usually greater than $50 \%$ of the tensile breaking load and that the minimum be sufficiently low, near to zero load. The minimum load criterion has been found to differ with different fibres [4].

The structures of polyamide and polyester filters have been widely discussed in the literature [5-7] and it is known that they are semicrystalline consisting of blocks of well-ordered molecules linked by tie molecules and surrounded by irregular arranged molecules. The structures are anisotropic having a preferred molecular orientation parallel to the fibre axis due to the drawing process.

Transmission electron microscopy was used in order to study local modifications of the fibre structure particularly around the fatigue crack tip. The fibre was embedded in epoxy resin and 
then sliced with an ultramicrotome giving specimens with thicknesses of 500-1000 $\AA$. The technique have been used extensively for the study of fibres [8-10] and has been described in detail in the literature [11].

Electron diffraction studies have been made in the neighborhood of the crack tip. These proved difficult with normal beam intensities because of radiation-induced damage producing an amorphization of the structure [12]. The location of the diffracted areas studied was assured after the pattern was taken in low dose conditions, by irradiating these zones with an intense electron beam which resulted in a clear area on the micrograph.

The diffracting area was a disk of about $0.5 \mu \mathrm{m}$ diameter so that with a thickness of approximately $800 \AA$ the diffracting volume was around $1.6 \times 10^{-20} \mathrm{~m}^{3}$ or $10^{7}$ smaller than that studied by $x$-ray diffraction.

Figure 3 shows an oblique transverse section of a fibre which contained a fatigue crack. It can be seen from the electronic diffraction micrographs that the crystallinity in the zones near to the crack tip was greatly reduced. This halso been revealed with more global measurements using $\mathrm{x}$-ray diffraction and infrared spectroscopy.

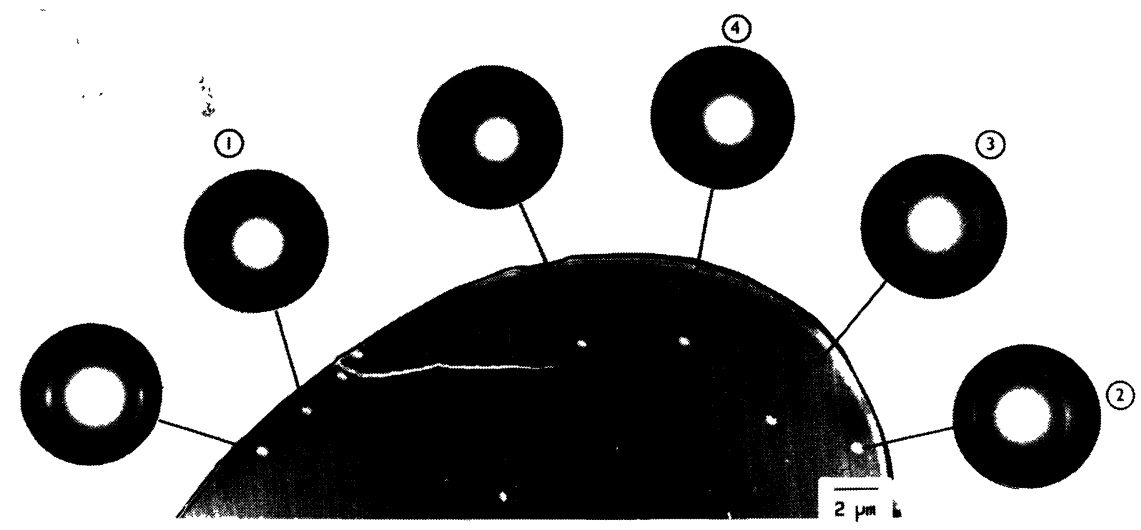

Fig. 3. - Electron diffraction patterns obtained with a section through the tip of a fatigue crack in a polyester fibre.

Figure 4 shows part of an oblique longitudinal section of a fibre which contained a fatigue crack. It can be seen that the crack was preceeded by a band of less dense material and that just ahead of the crack tip a series of micro voids were visible. Dark field micrographs obtained from the (110) and (100) diffraction spots isolated from the equatorial reflections revealed an absence of bright areas corresponding to crystallites and an accumulation of drawn out amorphous zones, particularly near the fatigue crack tip.

These observations made by transmission electron microscopy, together with information obtained with other analytical techniques and measurements such as that of the variation of internal energy absorption during the fatigue of fibres have allowed a complete understanding of the fatigue process to be obtained [13].

The ordered crystalline blocks in the microfibrils are linked by tie molecules which are aligned, although not perfectly, in the fibre axis direction. Loose randomly arranged molecules also occupy 


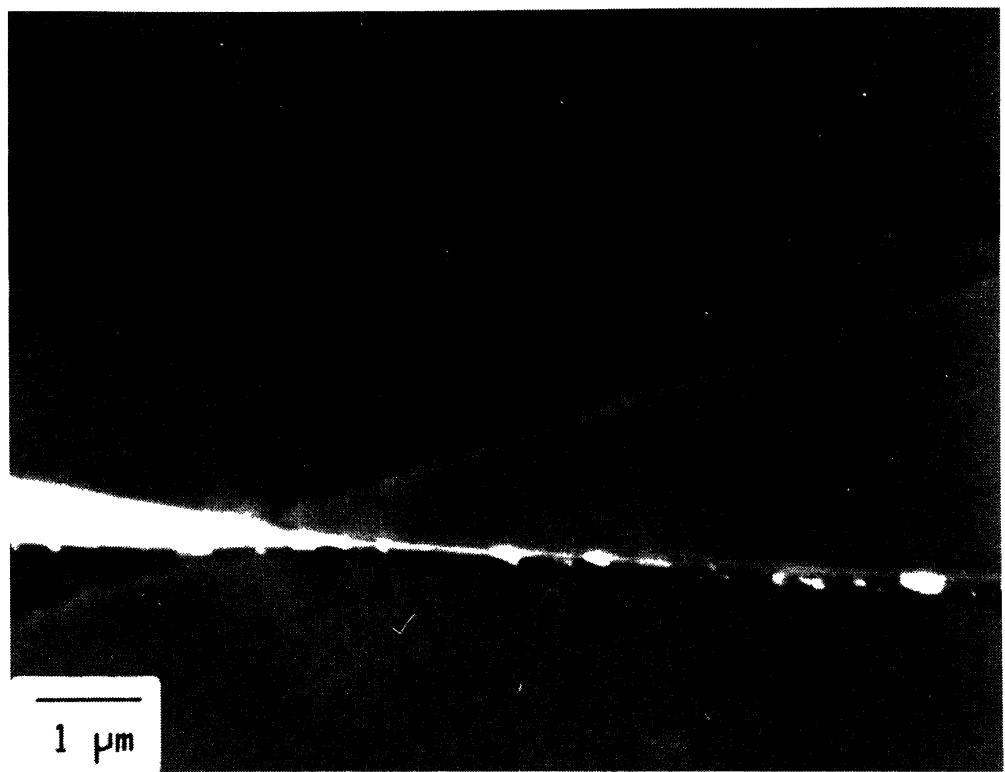

Fig. 4. - Details of a fatigue crack in polyester showing that it is preceeded by micropores (TEM image bright filed mode).

the space between the crystallites. Between microfibrils aligned molecules make up what we have called the mesomorphous phase. Figure 5 illustrates the state of the molecular structure during loading and unloading.

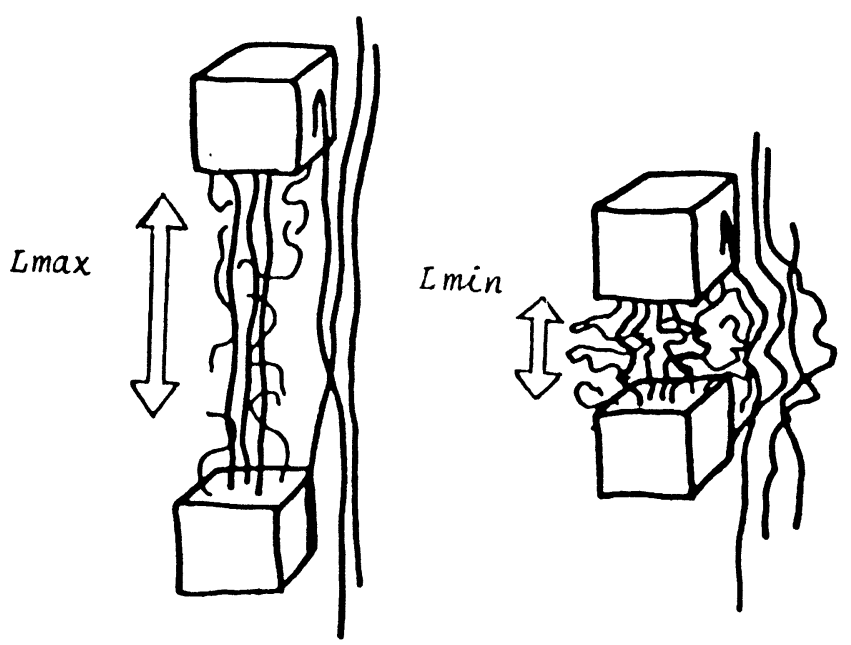

Fig. 5. - Representation of the microfibrillar structure of polyester fibres during extension and under low loads. 
The initiation of a fatigue crack involves the damage of the interfibrillar interface resulting in the decohesion of microfibrils. This process is accompanied by a reduction in the number of molecular chains in the trans configuration as revealed by infrared spectrosocpy and a fall, locally, in crystallinity as shown by $x$-ray analysis and electron diffraction studies. The role of the amorphous phases is called into question by the results of the hysteresis reported above. The physical mechanisms controlling fatigue crack initiation are the induced shear forces developed in the interfibrillar zone due to the differences in compliances between the microfibril and the mesomorphous zones. A sufficiently low minimum load produces sliding, movement and bending of molecular chains in the interfibrillar zone and in the intrafibrillar amorphous zones. This leads to an increase in dissipated energy within the amorphous phase.

This study has therefore revealed how, by engineering the fibre molecular morphology, notably by changing the densities of the inter and intra fibrillar amorphous zones, the fatigue behaviour of the fibre and hence that the complete composite structure can be controlled.

1.2 CARBON FIBRES. - Advanced composites are most often associated with carbon fibres which, since their development in the 1960's, have revolutionised the aerospace industry. The properties of carbon fibres can be greatly modified by heat treatment and an understanding of the mechansims governing their behaviour has only become possible by studies using transmission electron microscopy. Specimens of the fibres are normally prepared for the microscope by ultramicrotomy.

Carbon is one of the lightest elements being placed sixth in the periodic table. It is therefore extremely light in weight and is remarkable as it retains its properties up to $2000^{\circ} \mathrm{C}$ and above. It can take several forms and in its octahedral crystalline state, which is diamond, it is the hardest material known.

Carbon fibres are, in a sense, the original artificial fibre as Edison produced them by carbonizing cellulosic fibres, bamboo or cotton, to make the original filaments for the earliest incandescent electric lamps.

Although the work of Edison and some other early inventors is reminiscent in some ways of modern carbon fibre production it was not until the late 1950's that work began that was to lead to the fibre used in todays composites. Carbon fibres can be made from many different precursors [14]. The basic requirement being that the fibre carbonizes on heating rather than melting. Work to produce carbon fibres in the U.S.A. during the 1950, like that of the earlier work of Edison, was based on cellulose. Cellulosic regenerated fibres were slowly pyrolized to give flexible carbon fibres [15]. The slowness of the process, a low carbon yield of about $25 \%$ of the original weight, both of which increased costs coupled with less than optimum mechanical properties has meant that this manufacturing route has not dominated carbon fibre production.

Carbon fibres made from rayon which is not held under tension during carbonisation have a crystalline structure which is poorly organised even if it does possess an inherent directionality due to the structure of the precursor fibre. Such fibres possess a Young's modulus of approximately that of glass with about $20 \%$ of its strength. Such fibres have considerably lower densities than that of dense graphite and electron microscopy suggests that much of the fibre structure is porous with pores measuring up to $10 \mathrm{~nm}$ in diameter. The strength of these fibres falls with heat treatment. High performance carbon fibres can only be produced if the fibre structure is orientated which is achieved by hot stretching during the graphitization stage. This process aligns the graphite planes preferentially more or less parallel to the fibre axis and at the same time reduces the pore sizes. Properties can be considerably enhanced in this way with increases in Young's modulus greater than five times and of strength four times being possible [16]. The improvement in fibre structure produces both an increase in Youngs modulus and an increase in strength.

This type of carbon fibre finds some use today as the reinforcement for some carbon-carbon 
composites but has mainly been displaced by fibres derived from polyacrylonitrile precursors.

Most of the carbon fibres used today for reinforcing composites owe their origin to a pioneering work in Japan by Shindo and his colleagues who based their studies on polyacrylonitrile (PAN), precursor filaments [17]. This work was however anticipated by more than ten years by Houtz in Great Britain who studied the effects of heat on Orlon, which is a polyacrylonitrile [18]. This early work showed that the Orlon fibres heated to $200^{\circ} \mathrm{C}$ in air turned black and lost about $30 \%$ by weight but still retained more than half their original strength. Studies at the Royal Aircraft Establishment in Great Britain eventually produced the first commercially viable carbon fibre from PAN precursors [19]. This fibre became available commercially in 1967. Fibres produced from PAN precursors proved to give a higher carbon yield than the cellulosic route, they were also quicker to produce and possessed superior mechanical properties. The appearance of the PAN fibre suggests a fibrillar structure which is revealed by the striations on the fibre surface. The carbon fibres retain this outward appearance.

If outwardly the carbon fibre retains aspects of the precursor fibre, transmission electron microscopy has revealed that its internal structure also retains a directionality imposed on the microstructure of the precursor fibre during its manufacture [20]. The structure of carbon fibres consists of ribbons of aromatic layers lying approximately parallel to the fibre axis but in complete rotational disorder in the plane normal to the fibre axis. Where the adjacent aromatic ribbons touch bonding takes place and ensures the fibre's cohesion. Such a structure is not optimumly packed and contains many open spaces or pores. The less welded are the aromatic layers the more open is the structure and the larger the pores [21]. The ribbon can be more or less twisted and considerable differences have been found in the average twist angle as determined by transmission electron microscopy between different commercially available carbon fibres.

The exact structure of the ribbons is open to some dispute. Some authors have considered the sheets to be continuous graphite sheets $[20,21]$ but other studies suggest that they are composed of small collections of aromatic groups known as basic structural units (BSU) [22]. These BSU represent, for a turbostratic material, the equivalent of the crystallite for a crystallized material. High tensile strength fibres are made of very small BSU with dimensions of less than $1 \mathrm{~nm}$. Being made up of small BSU formed however into long sheets it is possible to see how these sheets can bend and branch so ensuring lateral cohesion. Pores in the fibre are elongated approximately parallel to the fibre axis and the surface of the pores made up of the basic structural units lying in the plane of the surface. Figure 6 shows a longitudinal section of a high strength carbon fibre and reveals the elongated pores parallel to the fibre axis. Figure 6 has been provided by Guigon of the Technology University of Compiegne.

High modulus carbon fibres are found to possess larger BSU units with dimensions up to $10 \mathrm{~nm}$ and to have more regular and continuous structures with fewer pores. This type of structure would be expected to yield a higher modulus and lower strength. Figure 7 reveals a transversal section of a high modulus carbon fibre and shows few signs of pores than is the case with high strength fibres. Figure 7 has also been provided by Guigon.

1.3 FINE CERAMIC FIBRES. - Small diameter ceramic fibres began to become available in the early 1980's. They immediately attracted attention as candidates as reinforcements of high temperature composites and as such offer the possibility of creating a new class of refractory structural materials for use above $1000^{\circ} \mathrm{C}$.

Those small diameter ceramic fibres which have become available for testing have either been based on alumina or silicon. The first fibres of this types to be produced were made by ICI in 1972 as a refractory felt and consisted of $\delta$-alumina with three percent silica. These fibres, which are called Saffil, were produced originally as a refractory insulator but have become the most widely used reinforcement for light alloys. The first continuous fibres were produced at the end of the 


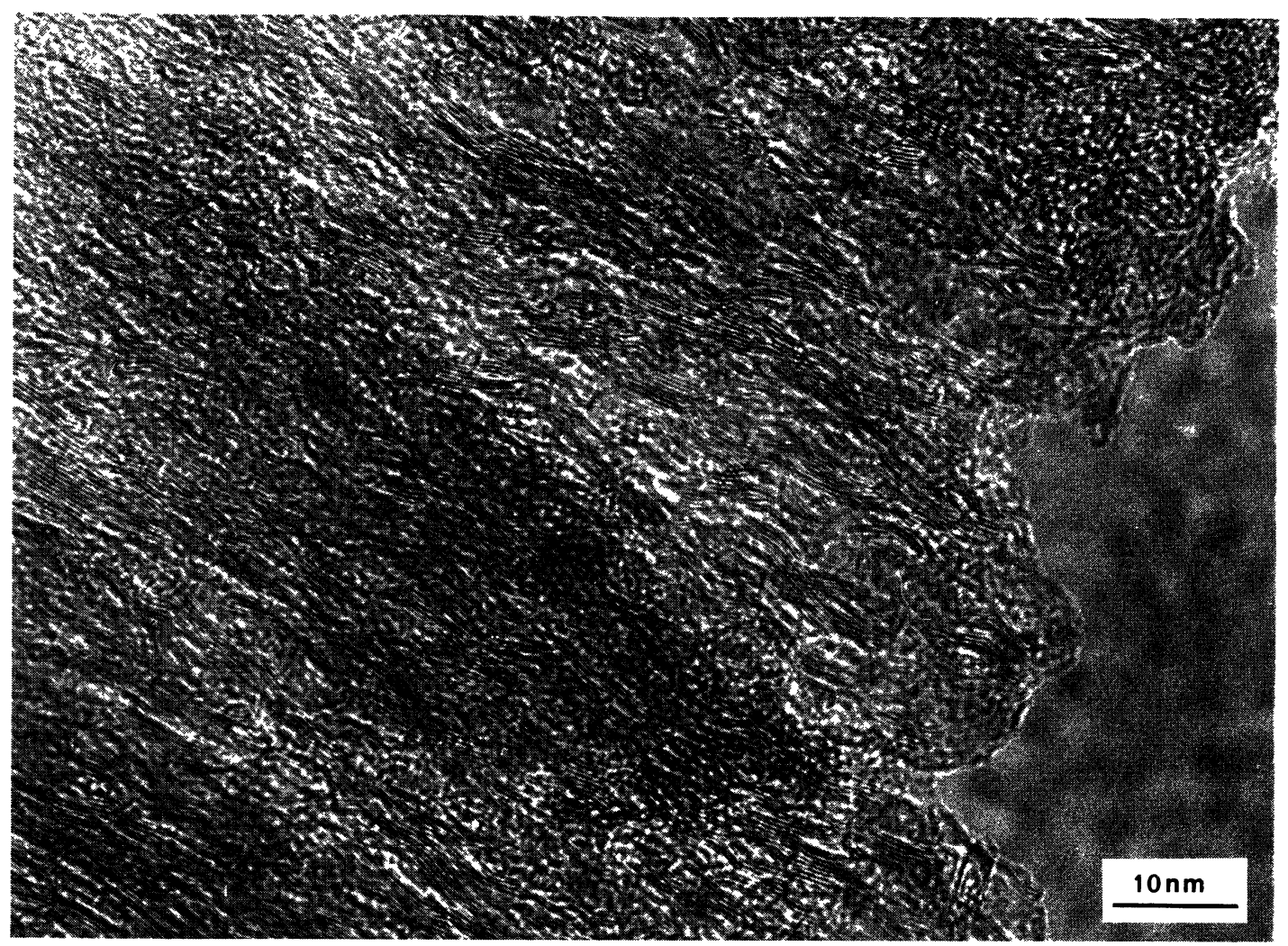

Fig. 6. - Longitudinal section of a high strength carbon fibre revealing elongated pores parallel to the fibre axis.

1970's by Du Pont de Nemours under the trade name Fibre FP and consisted of almost pure $\alpha$ alumina. Fibres FP has a modulus of $380 \mathrm{GPa}$ which is high but a breaking strain which is low, being $0.4 \%$. The fibre is extremely brittle due to it having a large grain size of about $0.5 \mu \mathrm{m}$ which is a significant fraction of its diameter which is $20 \mu \mathrm{m}$. More recently du Pont has produced a fibre called PRD-166 which is described as consisting of $80 \%$ by weight of $\alpha$-alumina and $20 \%$ partially stabilized zirconia.

The PRD-166 fibre has a strain to failure fifty percent higher than that of the Fibre FP. This is accounted for by the manufacturer by a phase change of the zirconia limiting grain growth at high temperatures and subsequently producing a small grain size in the fibre. This may or may not be the explanation but it is clear that only examination by transmission electron microscopy can be expected to give us a clearer picture of the mechanisms governing strength.

Specimen preparation for the transmission electron microscope can be by ultramicrotomy but this fragments the fibre. Ion beam etching seems to be a more reasonable technique which allows thin sections of the fibres to be obtained from polished specimens consisting of fibres embedded in a matrix. The specimens are first reduced in thickness to approximately $50 \mu \mathrm{m}$ and then reduced to a tapering section of less than $50 \mathrm{~nm}$ by ion bombardment as illustrated in figure 8 . An examination of the microstructure has revealed that it consists of $\alpha$-alumina grains with two size population averaging $0.8 \mu \mathrm{m}$ and $10 \mathrm{~nm}$ and zirconia grains with sizes of $0.1 \mu \mathrm{m}$ and $10 \mathrm{~nm}$ as illustrated by the dark field micrograph in figure 9. It is possible that the few large grains of alumina control the 


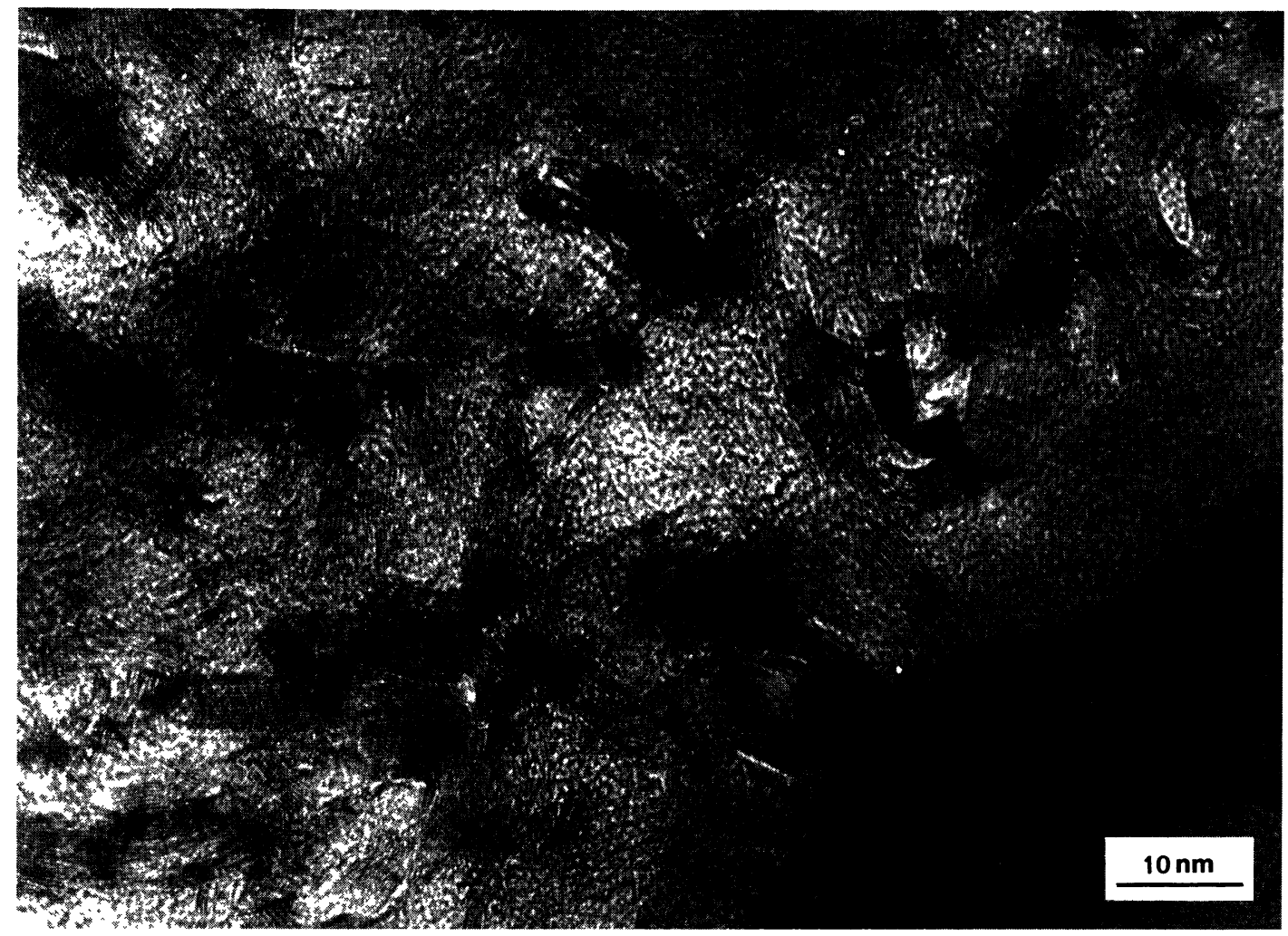

Fig. 7. - Transversal section of a high modulus carbon fibre showing few signs of pores.

breaking strength of the fibre as little change in properties is observed after heat treatment for several hours at $850^{\circ} \mathrm{C}$ even though the microstructure is greatly modified, notably with growth of the smaller grain [23].

Another fibre which contains $85 \% \gamma$-alumina and $15 \%$ silica is produced by Sumitomo Chemicals. The silica content produces a fibre with a reduced Young's modulus of around $180 \mathrm{GPa}$ and a strain to failure of $1 \%$. Transmission electron microscopy reveals that the microstructure of the fibre is very different from those based on $\alpha$-alumina. Figure 8 shows that $\gamma$-alumina grains have a size between 10 and $25 \mu \mathrm{m}$ and are embedded in an amorphous silica matrix. These fibres are found to conserve their mechanical properties up to 800 to $1000^{\circ} \mathrm{C}$ but that a dramatic fall in strength and modulus occurs at around $1150^{\circ} \mathrm{C}$. The fibre is found to creep at $1000^{\circ} \mathrm{C}$ and above and that prolonged exposure at temperatures above $1100^{\circ} \mathrm{C}$ produced accelerated creep behaviour [27]. An examination of the microstructure after one hundred hours exposure at $1127^{\circ} \mathrm{C}$ produced the microstructure shown in figure 9 revealing large grains of mullite $0.3 \mu \mathrm{m}$ in size. The behaviour of the fibre at high temperatures has been shown, with the use of transmission electron microscopy backed up by other techniques, to be controlled by softening of the amorphous silica matrix, making up $15 \%$ of the structure, intergranular diffusion and grain growth leading to conversion, to mullite.

Nicalon is the trade name given by Nippon Carbon to the best known ceramic fibre and which it produces and which is based on silicon carbide. The fibre is made by the conversion of a polycarbosilane precursor fibre which is crosslinked in the presence of oxygen and then pyrolysed [25]. 


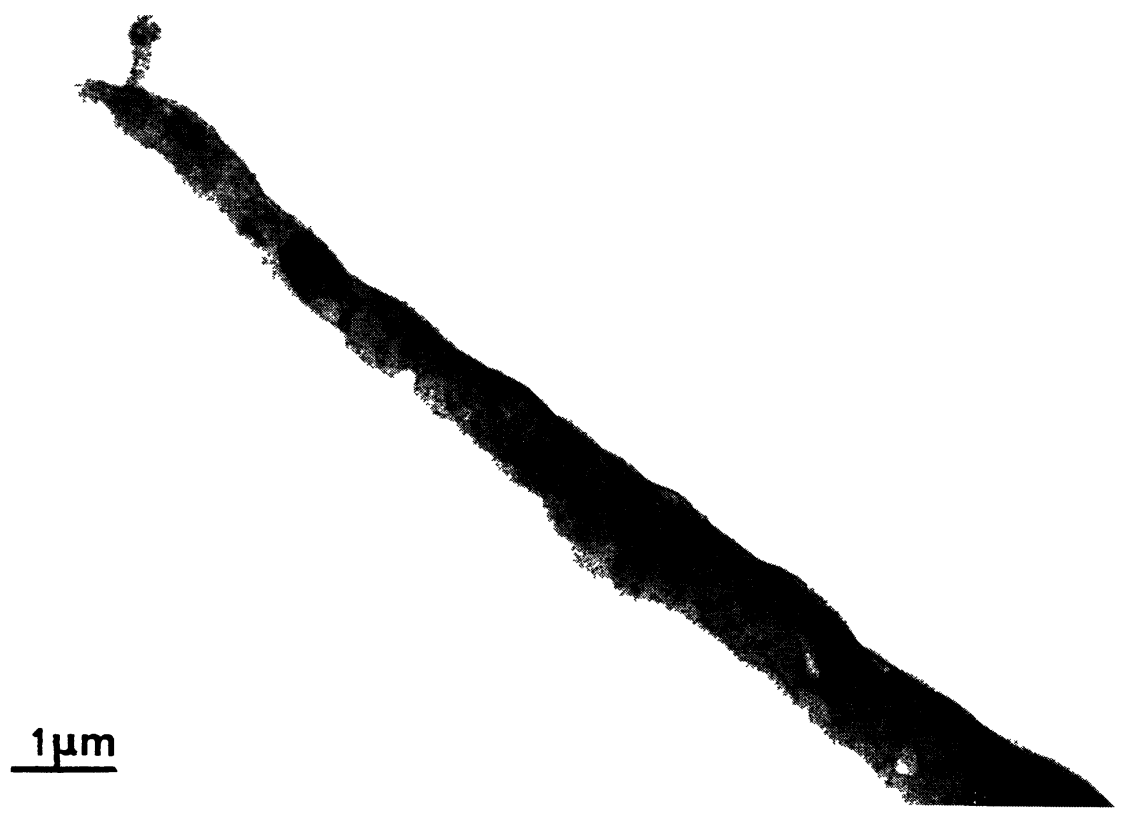

Fig. 8. - The ceramic fibre is first reduced in cross section by polishing and then by ion etching to allow examination by transmission electron microscopy of the section of about $50 \mathrm{~nm}$ thickness (bright field mode).

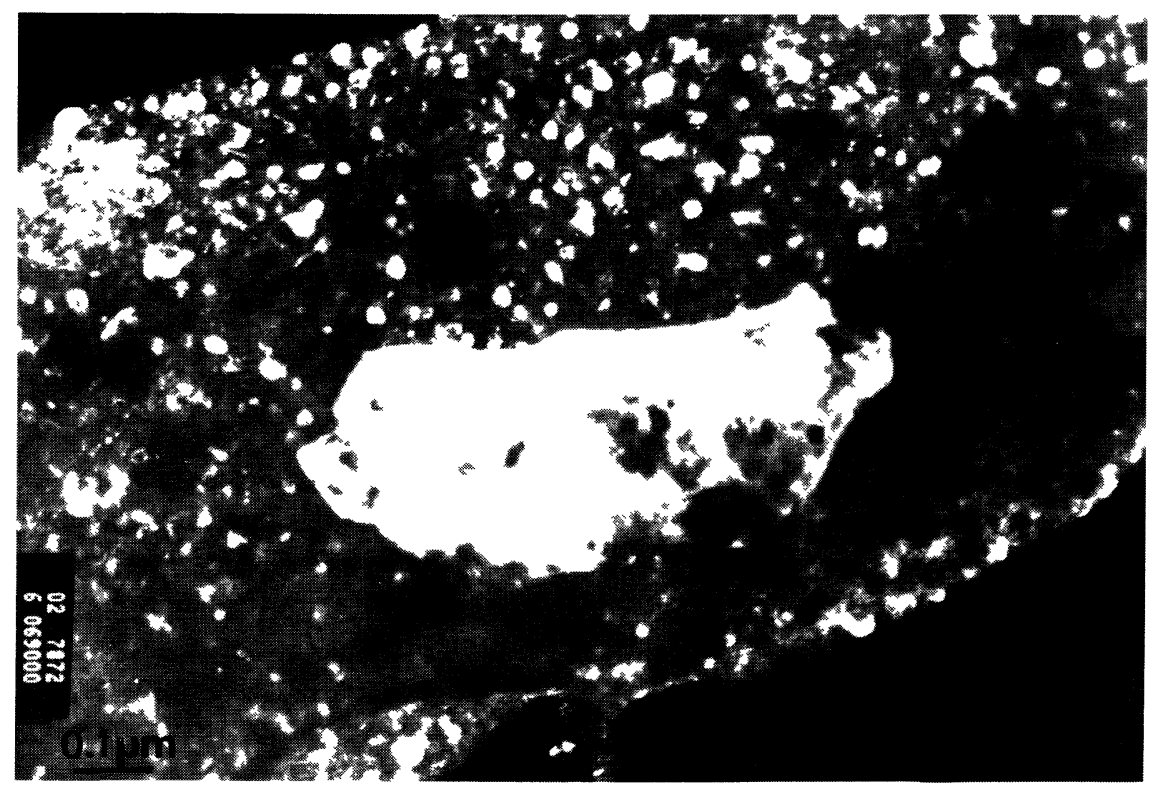

Fig. 9. - The PRD-166 fibre is seen to consist of large grains of $\alpha$-alumina and zirconia having sizes respectively of around $0.7 \mu \mathrm{m}$ and $0.1 \mu \mathrm{m}$ surrounded by smaller crystals, of the same materials, having sizes of about $10 \mathrm{~nm}$ (TEM image, dark field mode). 
The fibre contains approximately $65 \mathrm{wt} \%$ of $\mathrm{SiC}, 15 \%$ free carbon and $20 \mathrm{SiO}_{2}$. The strength and Young's modulus of Nicalon fibres show little change up to $1000^{\circ} \mathrm{C}$. Above this temperature both these properties fall with the greatest change being in strength of the fibre $[26,27]$. The fibres are also found to creep above $1000^{\circ} \mathrm{C}$ [28]. Transmission electron microscopy revealed that the fibres were originally almost amorphous with grain sizes less than $2 \mathrm{~nm}$. Heating above $1100^{\circ} \mathrm{C}$ produced grain growth with stabilisation at a size of $3 \mathrm{~nm}$. Under no applied load this resulted in shrinkage but if the applied stress was sufficiently high the fibre crept. Primary creep or shrinkage was controlled by grain growth and transmission electron microscopy suggested that a heat treatment to stabilise the microstructure would reduce both considerably. The result has been a new generation of fibres which have been heat treated to stabilise grain growth and which have improved properties at high temperature.

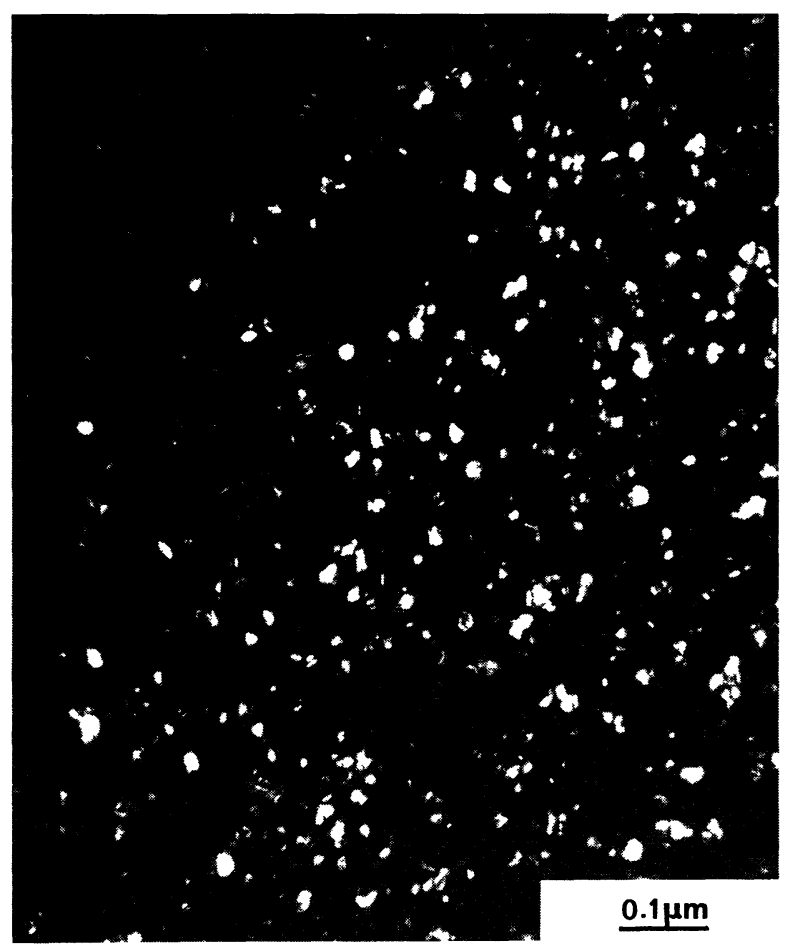

Fig. 10. - Dark field electron micrograph of the alumina-silica fibre from Sumitomo chemicals showing crystals of $\gamma$-alumina of approximately $12 \mathrm{~nm}$. 


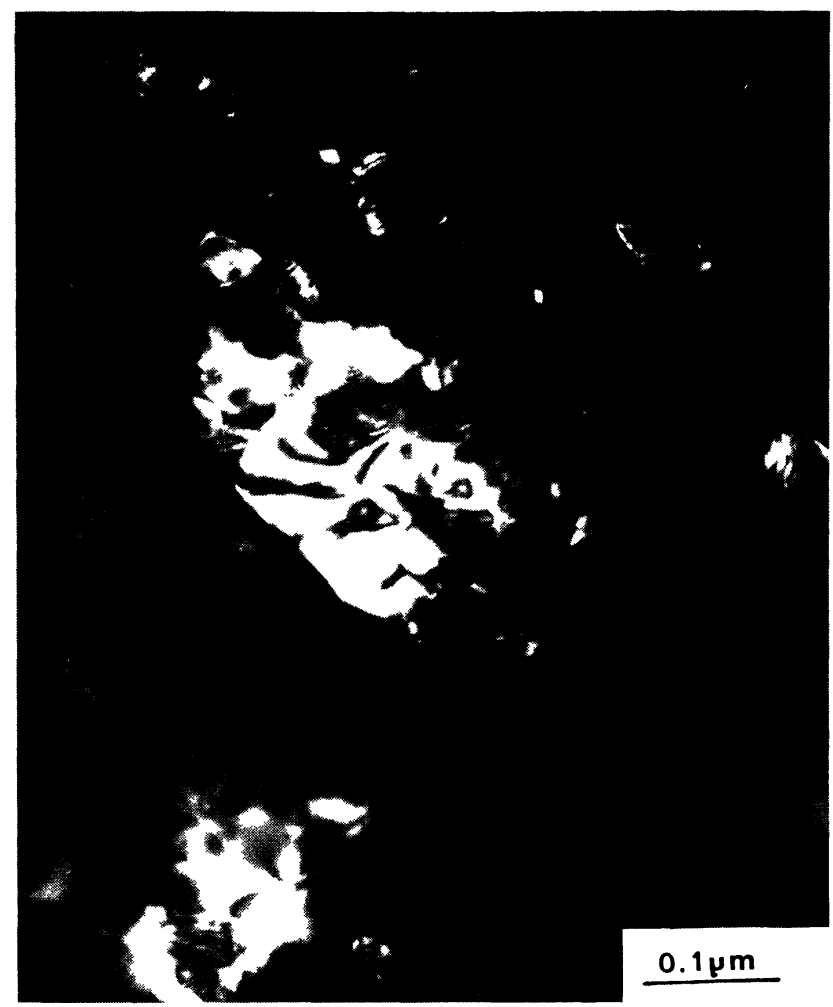

Fig. 11. - Heat treatment at $1127^{\circ} \mathrm{C}$ for one hundred hours of the alumina-silica fibre from Sumitomo chemicals produced large mullite crystals surrounded by much smaller $\gamma$-alumina grains (TEM image, dark field mode).

\section{Conclusion.}

The reinforcements of composite materials are fine filaments and it is their behaviour which often governs the potential use of the composites. Improvements to their properties can be made only if the mechanisms controlling their behaviour are identified and understood. In order to achieve this goal fibres have to be tested under conditions of loading, temperature and environment which simulate their use in composite structure. Having mechanically characterised the fibres a study of their microstructure can reveal those physical and chemical mechanisms which control their behaviour. To do this a variety of techniques are employed however we have seen that transmission electron microscopy is a particularly powerful tool for revealing the fundamental processes governing behaviour and has permitted the improvement of wide range of very different reinforcements. 


\section{References}

[1] Bunsell A. R., Fibre Reinforcements for Composite Materials (Elsevier Amsterdam, (1988).

[2] Bunsell A. R. and Hearle J. W. S., J. Appl. Polym. Sci. 18 (1974) 267.

[3] Bunsell A. R. and HeARle J. W. S., J. Mater. Sci. 6 (1971) 1303.

[4] OUdET Ch. and Bunsell A. R., J. Mater. Sci. Lett., to appear.

[5] Hearle J. W. S. and Greer R., Text. Prog. 2 (1970) 203.

[6] Peterlin A., Text. Res. J 42 (1972) 20.

[7] MERedith R., Text. Prog. 7 (1975) 74.

[8] ReimsChuesSEl and Prevorsek D. C., J. Polym. Sci. 14 (1976) 485.

[9] BennetT S. C. and JoHnson D. J., Carbon (Pergamon, New York) 17 (1979) 25.

[10] Johnson D. J., Phil. Trans. Roy. Soc. Lond. A.294 (1980) 443.

[11] Hagege R. and Hegege J., Technique de Laboratoire (Masson, Paris)4 (1980) 123.

[12] Vève J. Ch., Bunsell A. R. and Baillie C., Kautschuk + Gunni, Kunstoffer 40 (1987) 10, 941.

[13] SitTig M., Carbon and Graphite Fibres-Manufacture and applications, Noyes, Data Co., N. J. (1980).

[14] Cranch G. E., Proc. 5th Conf. Carbon, (Permagon 11 (1962) 589.

[15] BACON R. and SHALAMON W. A., Physical properties of high modulus resistant fibres from organic polymers, J. Preston Ed. (Interscience N. Y. 1969) p. 285.

[16] SHINDO A., FuJII R. and SENGOKY M., Japanese Patent (1962) p. 4405.

[17] HOUTZ R. C., Tex. Res. J. 20 (1950) 11.

[18] FITZER E. and HEviRE M., Carbon Fibre Manufacture and Surface Treatment in "Fibre Reinforcement for Composite Materials", A. R. Bunsell Ed. (Elsevier Amsterdam, 1988) p. 73.

[19] OBERLIN A. and GUIGON M., "The structure of carbon fibres" in Fibre Reinforcements for Composite Materials, A. R. Bunsell Ed., (Elsevier, 1988) p. 149.

[20] GUIGON M., OBERLIN A. and DESARMOT G., Microtexture and Structure of some high tensile strength Pan based carbon fibre", Fibre Sci. Tech. 20 (1984) 55.

[21] Reynolds W. N., Chem. Phys. Carbon 11 P. L. Walker and P. A. Thrower, Eds., Dekker, N. J. (1973).

[22] BENNET S. C., JOHNSON D. J. and JOHNSON W., "Strength structure relationships in PAN based Cfibres", J. Mat. Sci. 18 (1983) 3337.

[23] LAVASTE V., BERGER M. H., BunSEll A. R.. "Strength and microstructural analysis of PRD 166 fibre" Proc. ECCM4, J. Füller Ed. (Elsevier, 1990) p. 561.

[24] LESNIEwSKI Ch., AUBIN C., BUNSELl A. R., "Property Structure Characterisation of a Continuous Fine Alumina - Silice Fibre" Compos. Sci. Tech. 37 (1990) 63.

[25] Yajima S., HaSe GaWa Y., Hayashi J. and IimuRa M., "Synthesis of continuous silicon carbide fibre". Part I, J. Mat. Sci. 13 (1978) pp. 2569-2576.

[26] SiMON G. and BUNSELL A. R., "Mechanical and structural characterization of the Nicalon silicon carbide fibre", J. Mat. Sci. 19 (1984) pp. 3649-3657.

[27] SimON G. and BUNSELL A. R., "Creep behaviour and structural characterization at high temperature of Nicalon SiC fibres”, J. Mat. Sci. 19 (1984) p. 3658.

[28] BUNSELl A. R. and SiMON G., "Mechanical and structural characterization of Nicalon SiC. Fibres up to $1300{ }^{\circ}$ C", Compos. Sci. tech. 27 (1986) 157. 